\title{
Sero-prevalence and occupational risk factors for Brucella infection among slaughterhouse workers and butchers in Kumasi, Ghana
}

\author{
Esimebia Adjovi Amegashie ${ }^{1}$, Ellis Owusu-Dabo ${ }^{1,2}$, Samson Pandam Salifu ${ }^{1}$, Anthony Afum-Adjei Awuah ${ }^{1}$, Sandra \\ Baffour-Awuah $^{1}$, Nicholas Addofoh ${ }^{1}$, Augustina Annan*1,3 ${ }^{*}$ Christian Henrik Winter ${ }^{4}$ \\ ${ }^{1}$ Kumasi Centre for Collaborative Research (KCCR), Kumasi, Ghana \\ ${ }^{2}$ School of Public Health, Kwame Nkrumah University of Science and Technology, Kumasi, Ghana \\ ${ }^{3}$ Department of Theoretical and Applied Biology, Kwame Nkrumah University of Science and Technology, Kumasi, Ghana \\ ${ }^{4}$ Bernhard Nocht Institute of Tropical Medicine (BNITM), Hamburg, Germany
}

Received: July 15, 2016

DOI: $10.5430 /$ jer.v3n1p17
Accepted: September 1, 2016

Online Published: September 18, 2016

\begin{abstract}
Brucellosis remains neglected in many countries despite its public health importance. In developing countries such as Ghana, there remains paucity of data particularly among high-risk populations such as slaughterhouse workers. The aim of this study was to determine the prevalence of Brucella infection and risk factors for its transmission among people working in and around slaughterhouses. A cross-sectional study was carried out with 220 participants selected through a stratified sampling method. Participants were interviewed about their knowledge on Brucella and their occupational activities using a structured questionnaire. Collected serum samples were analyzed for anti-Brucella Immunoglobulin M (IgM) and Immunoglobulin G (IgG) antibodies using the enzyme-linked immunosorbent assay method. Data was analyzed using uni-and multivariate logistic regression models. From 220 participants, anti-Brucella IgM- and IgG antibodies were detected in $4(1.8 \%)$ and 21 (9.6\%), respectively. 9.3\% of the participants with animal contact at work (5/54) and $11.5 \%$ of those working in meat processing (17/148) have heard about Brucella and its transmission mode. Most of the anti-Brucella IgG seropositive individuals (17/21) were working in the meat processing category (OR 2.2; 95\% CI 0.6-7.9; $p=.22$ ). Multivariate analysis showed that job duration was significantly associated with seropositivity to Brucella IgG (OR 1.31; 95\% CI 0.9-1.8, p-value .03). The findings demonstrate recent and past Brucella infections among workers of the Kumasi abattoir with a high risk for less educated meat processing staff. Thus, intensive educational programmes on Brucella designed for workers with high risks and improving workplace protection policy are recommended.
\end{abstract}

Key Words: Brucella, Infection, Slaughterhouse, Butchers, Risk factor

\section{INTRODUCTION}

Brucella species are Gram-negative rod-shaped bacteria that can cause life-long lasting chronic disease in humans. Of the six identified Brucella species, the most significant ones for causing zoonotic infections are B. abortus, B.melitensis and B. suis. Transmission of Brucella from infected livestock (mainly cattle and goats) to humans can either be direct through contact with infected material, or indirect through

*Correspondence: Augustina Annan; Email: annan@kccr.de; Address: Kumasi Centre for Collaborative Research (KCCR), Kumasi, Ghana. 
consumption of contaminated animal products.

More than 500,000 new cases of the infection are reported annually. ${ }^{[1]}$ However, the World Health Organization (WHO) suggests that this figure has been underestimated. ${ }^{[2,3]}$ Despite this underestimated figure, brucellosis remains neglected as a public health disease in livestock and humans. Occupational exposure predisposes shepherds, butchers, laboratory workers, veterinarians and abattoir workers to a high risk of Brucella infection through inhalation of contaminated aerosols, or entry of the bacteria through skin lesions after contact with infected animals or their products. ${ }^{[4-7]}$

All age groups are at risk of Brucella infection. However, some studies showed that more males than females were infected with Brucella and it was concluded that this was likely due to their occupational exposures as slaughterhouse workers and butchers. ${ }^{[8]}$

In developed countries, massive eradication campaigns in the 1970s and 1980s resulted in the elimination of bovine brucellosis and a substantial decline in its incidence in humans, ${ }^{[2]}$ whereas the same cannot be said for most developing countries. In endemic areas of Latin America for example, human populations are infected with Brucella species. ${ }^{[9]}$ In the Middle East, a study in humans with direct contact with animals revealed $14 \%$ and $11 \%$ seroprevalence based on the Rose Bengal plate test (RBPT) and enzyme-linked immunosorbent assay (ELISA) respectively. ${ }^{[10]}$ Other findings related to human brucellosis have also been reported in Bangladesh (4.4\%), India (15.6\%), Iran (7.1\%) and Turkey $14.22 \% .^{[11-14]}$ In Africa, a sero-survey of Brucella infection carried out in Uganda observed that up to $10 \%$ of human participants in three sub-counties in Kiruhura district were positive. ${ }^{[15]}$ A recent study carried out in Sudan reported a seroprevalence of $9.5 \%, 15.3 \%, 24.4 \%$ and $26.5 \%$ in veterinarians, meat inspectors, abattoir workers and animal handlers respectively. ${ }^{[16]}$ A seroprevalence of $40 \%$ among high-risk groups has also reported in Libya. ${ }^{[17]}$

In West Africa, Nigeria confirmed endemicity of bovine brucellosis among slaughtered cattle using the ELISA, showing that it is an occupational hazard to workers directly involved in cattle meat processing. ${ }^{[18]}$

In Ghana, livestock rearing remains a common source of income and serves as an important source of protein to majority of the population. With an increase risk of transmission of Brucella infection from livestock to humans, unfortunately, very little is known about its burden especially among humans in Ghana. In 2000, one study could not detect Brucella infection in humans by Rose Bengal Test (RBT), in selected risk groups in the Akwapim South district of Ghana. ${ }^{[19]}$ Stud- ies carried out at the Kumasi Abattoir focused on animal supply, logistic activities and their challenges, ${ }^{[20]}$ but failed to address critical issues like prevalence and occupational risk factors associated with handling livestock.

The known prevalence of Brucella infection and its associated risk factors will stir up the interest of researchers to conduct large epidemiological studies in order to control the spread of the infection among livestock rearers, butchers, abattoir workers and the populace as a whole. The aim of this study, therefore, was to determine the prevalence of Brucella infections and its risk factors among workers of the Kumasi Abattoir, an urban meat-processing factory in Ghana.

\section{METHODS}

\subsection{Design, area and population}

A cross sectional study was carried out at the Kumasi Abattoir, a meat factory located in suburban Kaase in Kumasi, the second largest city in Ghana. There are about 145 workers including kill floor workers, veterinarians, marketing staff, security staff and administrative workers. The kill floor workers are the line operators, slaughterers, butchers and meat processors. The abattoir also has about 195 auxiliary workers at its premises who are directly or indirectly involved with abattoir operations. These are meat sellers, livestock farmers and or traders, cowboys, loaders and drivers. In addition to the 145 abattoir workers, a total of 340 participants were targeted for the study.

Of the total 340 people working in and around the abattoir, $220(64.7 \%)$ were enrolled to participate in the study. This was based on their active involvement in slaughterhouse operations, their availability, and willingness to participate. Workers at the abattoir were between the ages of 16 and 78 .

\subsection{Sampling and sample size}

We used a stratified sampling method to select the study participants. Participants were divided into three groups based on the nature of their job/duties: (1) working in meat processing, (2) contact with animals and (3) others.

\subsection{Data collection}

We sought permission from all workers and the authorities at the abattoir before data collection started. The study aim and objectives were explained to participants in the local dialect. After obtaining informed consent, interviews were conducted using a structured questionnaire. Key questions were on their knowledge about Brucella infection and determinants of the infection including occupational information, handling of livestock at home, and consumption of animal and animal products. Data collection was conducted from May to August 2014. 


\subsection{Sample collection and analysis}

$4 \mathrm{ml}$ of blood was taken from each individual and transported at $2^{\circ} \mathrm{C}-8^{\circ} \mathrm{C}$ to the Kumasi Centre for Collaborative Research in Tropical Medicine (KCCR) laboratory for analysis.

Blood samples were centrifuged at 2,500 $\times \mathrm{g}$ for 5 minutes to obtain sera, which were stored at $-20^{\circ} \mathrm{C}$ before conducting the assays. Each serum was tested for anti-Brucella IgM and IgG antibodies using ELISA technique (Brucella IgG/IgMInstitut Virion/Serion GmbH, Germany).

For IgM antibodies, any antibody index of $<15 \mathrm{U} / \mathrm{ml}$ was considered as negative; $15-20 \mathrm{U} / \mathrm{ml}$ as borderline and $>20$ $\mathrm{U} / \mathrm{ml}$ as positive. For $\operatorname{IgG}$ antibodies, any antibody index of $<20 \mathrm{U} / \mathrm{ml}$ was considered as negative; $20-30 \mathrm{U} / \mathrm{ml}$ as borderline and $>30 \mathrm{U} / \mathrm{ml}$ as positive.

\subsection{Data analysis}

Data was entered intoEpi Info version 3.4.3 and analyzed using STATA version 12.0. Descriptive statistics of the variables were analysed and presented in the form of tables and graphs. Univariate analysis using logistic regression was conducted to check for collinearity among possible variables under investigation and anti-Brucella IgM and IgG antibodies. Only variables significant $(p \leq .05)$ during the univariate logistic regression analysis were considered for multivariate analyses. Odds ratios (OR) and their $95 \%$ confidence intervals were calculated. All associations with $p$ value $\leq .05$ were considered statistically significant.

\subsection{Ethical consideration}

The study was approved by the Committee on Human Research Publication and Ethics of the Kwame Nkrumah University of Science and Technology, Kumasi-Ghana (Ref No. CHRPE/AP/123/13).

\section{Results}

As shown in Table 1, almost all participants were males (218 males, 2 females) and the median age of the participants was 36.7 years $(S D \pm 11.4$, range 16-78 years). Seventyfour participants were illiterate $(33.6 \%)$ and 53 had only primary education $(24.1 \%)$. From the 220 participants, (1) 148 worked in meat processing $(67.3 \%)$, (2) 54 had occupational contact with animals (24.5\%), and (3) 18 had other jobs in and around the slaughterhouse (8.2\%).

All the four IgM positive sera were from individuals of the age group 30-39 years that were involved in meat processing: two butchers and two line operators. Two out of 74 illiterate study participants had anti-Brucella IgM antibodies (2.7\%), which was not significantly higher compared to participants with primary and secondary school education $(1.9 \%$ and $1.5 \%$, respectively).

Table 1. Distribution of IgM seropositivity by demographic

\begin{tabular}{lll}
\hline & Total & No of Pos. (\%) \\
\hline AGE & 52 & 0 \\
$<30$ years & 84 & 4 \\
30-39 years & 57 & 0 \\
40-49 years & 27 & 0 \\
50+ years & & \\
OCCUPATION & 54 & 0 \\
Animal contact & 148 & $4(2.7)$ \\
Meat processing & 18 & 0 \\
Others & & \\
EDUCATION & 74 & $2(2.7)$ \\
Illiterate & 53 & $1(1.9)$ \\
Primary & 68 & $1(1.5)$ \\
Secondary & 25 & 0 \\
Post-secondary & & \\
DUARTION ON JOB & & $2(2.7)$ \\
$<10$ years & 74 & $1(1.0)$ \\
10-19 years & 100 & $1(2.2)$ \\
20+ years & 46 & \\
\hline
\end{tabular}

As shown in Table 2, the age distribution of the $21 \mathrm{IgG}$ seropositive individuals was as following: 1/52 (2\%) was under 30 years, 10/84 (11.9\%) were 30-39 years old (OR $6.6 ; 95 \%$ CI $0.8-53.4 ; p=.08)$ and $7 / 57(12.3 \%)$ were $40-49$ years old (OR 7.0; 95\% CI 0.8-59.0; $p=.07$ ) while $3 / 27$ $(11.1 \%)$ were older than 50 years (OR 6.4; 95\% CI 0.6-64.8; $p=.12)$.

Additionally, most anti-Brucella IgG seropositive individuals $(17 / 21)$ were working in the meat-processing unit (OR $2.2 ; 95 \%$ CI $0.6-7.9 ; p=.22)$. $14.9 \%$ were illiterate while 9.4\% (OR 0.6; 95\% CI 0.2-1.8; $p=.37$ ) and 8.7\% (OR 0.3; $95 \%$ CI $0.1-1.0 ; p=.05$ ) had attained primary and secondary education respectively. Furthermore, $10 \%$ (OR 1.1; 95\% CI $0.4-3.0 ; p=.84$ ) of these IgG positive study respondents had worked for 10-19 years (see Table 2).

For multivariate analysis of Brucella IgG sero-positivity, the Odds Ratio (OR) for age was 1.15 (95\% CI 0.8-1.7; $p=.48$ ) while OR for occupation was 1.2 (95\% CI 0.8-1.8; $p=.39$ ). OR of duration on job was 1.31 (95\% CI 0.9-1.8; $p=.03$ ) while that of education was 0.4 (95\% CI 0.2-1.1: $p=.069)$ (see Table 3). There were no significant differences in age, occupation, educational level and handling of livestock. 
Table 2. Distribution of IgG seropositivity by demographic

\begin{tabular}{llllll}
\hline & Total & No of Pos. (\%) & COR & 95\% CI & P-value \\
\hline AGE & & & & & \\
$<30$ years & 52 & $1(2.0)$ & Reference & & .076 \\
30-39 years & 84 & $10(11.9)$ & 6.6 & $0.8-53.4$ & .074 \\
40-49 years & 57 & $7(12.3)$ & 7.0 & $0.8-59.0$ & .117 \\
50+ years & 27 & $3(11.1)$ & 6.4 & $0.6-64.8$ & \\
OCCUPATION & & & & & \\
Animal contact & 54 & $3(5.6)$ & Reference & & .220 \\
Meat processing & 148 & $17(11.5)$ & 2.2 & $0.6-7.9$ & .987 \\
Others & 18 & $1(5.6)$ & 0.9 & $0.1-10.1$ & \\
EDUCATION & & & & & \\
Illiterate & 74 & $11(14.9)$ & Reference & & .372 \\
Primary & 53 & $5(9.4)$ & 0.6 & $0.2-1.8$ & \\
Secondary & 68 & $4(8.7)$ & 0.3 & $0.1-1.0$ & \\
Post-secondary & 25 & 0 & N/A & & \\
DUARTION ON JOB & & & & & .894 \\
$<10$ years & 74 & $7(9.5)$ & Reference & & \\
10-19 years & 100 & $10(10.0)$ & 1.1 & $0.4-3.0$ & $0.3-3.3$ \\
20+ years & 46 & $4(8.7)$ & 0.9 & & \\
\hline
\end{tabular}

Table 3. Multivariate analysis of Brucella $\operatorname{IgG}$ sero-positivity

\begin{tabular}{llll}
\hline IgG & Odds Ratio & $\boldsymbol{P}$-value & 95\% Con Interval \\
\hline Age & 1.2 & .477 & $0.8-1.7$ \\
Occupation & 1.2 & .378 & $0.1-1.8$ \\
Education & 0.4 & .069 & $0.2-1.1$ \\
Duration on job & 1.3 & .030 & $0.9-1.8$ \\
Handling of livestock & 1.0 & - & - \\
\hline
\end{tabular}

As shown in Table 4, 53.2\% of the first group and $20.9 \%$ of the second group did not know about Brucella infection and its transmission modes.

Table 4. Relationship between occupation and knowledge about Brucella infection.

\begin{tabular}{lllll}
\hline \multicolumn{5}{c}{ Knowledge About } \\
\hline Occupation & No & Yes & Unknown & Total \\
Animal contact & $46(20.9 \%)$ & $5(2.3 \%)$ & $3(1.4 \%)$ & 54 \\
Meat processing & $117(53.2 \%)$ & $17(7.7 \%)$ & $14(6.4 \%)$ & 148 \\
Others & $7(3.2 \%)$ & $4(1.8 \%)$ & $7(3.2 \%)$ & 18 \\
Total & 170 & 26 & 24 & 220 \\
\hline
\end{tabular}

\section{Discussion}

Brucellosis is a major public health challenge in sub-Saharan Africa with socio-economic implications. ${ }^{[3]}$ Several people are at risk but individuals with certain occupations are considered to be at a higher risk of acquiring the infection. These include abattoir workers, veterinarians, butchers, cattle rearers and farmers. ${ }^{[21]}$

We employed an ELISA test to determine the sero-prevalence of Brucella infection among slaughterhouse workers and butchers. An observed prevalence of $9.6 \%$ for past infection is similar to a study from Nigeria among abattoir workers with a prevalence of $9.8 \%$ and a sample size of $224 .{ }^{[8]}$ However, this prevalence is lower when compared with a study carried out in a slaughterhouse in Nigeria $(21.7 \%) .{ }^{[22]}$ Our overall seropositivity rate for acute infection (1.8\%) was lower, compared to an Iranian study amongst slaughterhouse workers with a rate of $6.9 \% .{ }^{[13]}$ However, we are careful in comparing the findings of this work with that of other countries. This is because of geographical settings as the risk factors and the influence of the immediate environment might be very different. The risk of Brucella infection in the slaughterhouse setting may be strongly influenced by occupational practices, regular medical check-ups and measures put in place by the authorities in these countries. ${ }^{[23]}$

A study from Tanzania found a low anti-Brucella IgG seroprevalence of $5.5 \%$ in high-risk occupational groups like butchers and slaughterers. This might be explained by the fact that they used the less sensitive RBT. Other findings reported 15\% in Saudi Arabia ${ }^{[24]}$ among nomadic households using the Standard Tube Agglutination Test (STAT) with a 
sample size of 23,613 and 4.1\% in Brazil ${ }^{[25]}$ among high-risk group using the Complement Fixation Test (CFT) with a sample size of 645. A similar study carried out in Ghana, ${ }^{[19]}$ found no evidence of human Brucella infection in selected risk groups in the Akwapim South district of Ghana, using the RBT.

Most of the $\operatorname{IgG}(17 / 21)$ and all of the IgM seropositive individuals (4/4) were workers in the meat-processing unit, which included line operators, slaughterers, butchers etc. In addition, 10 of the $17 \mathrm{IgG}$ and 2 of the 4 IgM seropositives were line operators, who are responsible for dissecting animals and removing internal organs. This puts them in close contact with animal fluids, which is a great risk for contracting Brucella infections and consequently brucellosis. This finding is consistent with studies conducted in Greece ${ }^{[26]}$ and in Tanzania ${ }^{[27]}$ which indicated that the majority of cases with brucellosis were attributed to direct contact with animals and their products.

Our data indicated that age, occupation, educational levels and handling of livestock were not risk factors of brucella infection. This finding is in contrast with other studies in Yemen $^{[28]}$ and Turkey ${ }^{[29]}$ which showed that occupation and educational levels were significant risk factors for the infection.

We found a statistically significant association between length of service time at the abattoir and a high risk of chronic infection. This is plausible as the workers who have worked for a longer duration with repeated exposure to body fluids of potentially infected livestock, get infected. This is in line with an Iranian study ${ }^{[30]}$ that also highlighted a strong association between duration of occupational exposure and the Brucella infection.

The higher sero-positivity among the age group 30-49 years could be due to the fact that the majority of the active workforce at the abattoir falls in this age group. Comparable findings have reported an average age of 34.4 years in Kuwait, ${ }^{[31]}$ 33.8 years in Saudi Arabia ${ }^{[32]}$ and 31.6 years in Djibouti. ${ }^{[33]}$ The higher sero-positivity is observed in this age group due to them having been exposed longer to risk factors related to their occupation.

Three of the $21 \mathrm{IgG}$ positive individuals were also positive for IgM, which shows recent Brucella infection. These participants were given referral notes to the hospital for treatment. They were also educated on the possible transmission routes of the infection. They were further educated on ways to reduce infections and control the transmission of the infection.
Of concern is that only $9.3 \%$ of the participants working in the animal contact (5/54) and $11.5 \%$ of those with meat processing (17/148) reported any knowledge about Brucella and brucellosis though statistically insignificant. These workers are at the highest risk and in need of targeted public health education on Brucella including its transmission routes in slaughterhouses and the use of best protective practices. The educational material needs to be designed for illiterate workers and workers with primary education, so they know about the risk and are able to protect themselves. Additionally, protective clothing such as headgears, gloves, boots and others need to be provided for them.

Further studies should look at including other slaughterhouses across the country thereby increasing the sample size, power and representativeness. Culture method, which is the gold standard should be included to ascertain the prevalence of acute infection and also to provide treatment for those who will test positive.

\section{Conclusion}

Our findings demonstrate recent and past Brucella infections among workers of the Kumasi abattoir. Specific occupations like line operators and butchers show the highest risk of infection. Lower education and longer duration on the job were also associated with a higher risk of infection although insignificant.

We recommend that intensive educational programmes are conducted for the slaughterhouse workers on modes of transmission and prevention of Brucella infection in their work environment. Such programmes need to be targeted for workers that have the highest risks and designed in a way that messages can be understood by staff with lower education including the illiterate. Additionally, workers need to be provided with the required personal protective equipment to limit risk and spread of Brucella infection. Those with high risk professions should be referred to the hospital to be tested for the disease as soon as they develop even mild symptoms.

\section{ACKNOWLEDgements}

This research work was performed with funding from The African Programme for Advanced Research Epidemiology Training (2012/APARET/06). The study team is grateful to the staff and management of Kumasi Abattoir for the permission to carry out this work in their facility.

\section{CONFlicts OF InTEREST Disclosure}

Authors declare that they have no competing interests. 


\section{REFERENCES}

[1] Corbel MJ. Brucellosis: an overview. Emerging infectious diseases. 1997; 3(2): 213. PMid:9204307 http://dx.doi .org/10.3201/e id0302. 970219

[2] Corbel MJ. Brucellosis in humans and animals. World Health Organization. 2006

[3] Pappas G, Papadimitriou P, Akritidis N, et al. The new global map of human brucellosis. The Lancet Infectious Diseases. 2006; 6(2): 9199. http://dx.doi.org/10.1016/S1473-3099(06)70382-6

[4] Cutler S, Whatmore A, Commander N. Brucellosis-new aspects of an old disease. Journal of Applied Microbiology. 2005; 98(6): 12701281. PMid:15916641 http://dx.doi.org/10.1111/j.1365-2 $672.2005 .02622 . \mathrm{x}$

[5] Young EJ. Brucella species. In: Mandel GI, Bonnet JE, Dolin R editors. Principle and practice of infectious disease. 7th ed. New York: Churchill Livingstone. 201: 2921-5. http://dx.doi .org/10.10 16/b978-0-443-06839-3.00226-5

[6] Demiroglu YZ, Turunc T, Aliskan H, et al. Brucellosis: retrospective evaluation of the clinical, laboratory and epidemiological features of 151 cases. Mikrobiyol Bul. 2007; 41(4): 517-27. PMid: 18173070

[7] Mantur BG, Amarnath SK, Shinde RS. Review of clinical and laboratory features of human brucellosis. Indian J Med Microb. 2007; 25(3): 188. http://dx.doi.org/10.4103/0255-0857.34758

[8] Aworh MK, Okolacha E, Kwaga J, et al. Human brucellosis: seroprevalence and associated exposure factors among abattoir workers in Abuja, Nigeria-2011. Pan African Medical Journal. 2013; 16(103). http://dx.doi.org/10.11604/pamj.2013.16.103.2143

[9] Nimri LF. Diagnosis of recent and relapsed cases of human brucellosis by PCR assay. BMC Infect Dis. 2003; 3: 5. PMid:12718759 http://dx.doi.org/10.1186/1471-2334-3-5

[10] Hussain I, Arshad MI, Mahmood MS, et al. Seroprevalence of brucellosis in human, cattle and buffalo population in Pakistan. Turk J Vet Anim Sci. 2008; 32: 315-318.

[11] Agasthya AS, Isloor S, Prabhudas K. Brucellosis in high risk group individuals. Indian J Med Microbiol. 2007; 25: 28-31. PMid:17377349 http://dx.doi.org/10.4103/0255-0857.31058

[12] Nikokar I, Hosseinpour M, Asmar M, et al. Seroprevalence of brucellosis among high risk individual in Guilan, Iran. Journal of Research in Medical Sciences the Official Journal of Isfahan University of Medical Sciences. 2011; 16(10): 1366-1371.

[13] Rahman AK, Dirk B, Fretin D, et al. Seroprevalence and risk factors of brucellosis in a high risk group of individuals in Bangladesh. Foodborne Pathog Dis. 2012; 9: 190-197. PMid:22300225 http: //dx.doi.org/10.1089/fpd.2011.1029

[14] Otlu S, Sahin M, Atabay HI, et al. Serological investigations of brucellosis in cattle, farmers and veterinarians in the Kars district of Turkey. Acta Vet BRNO. 2008; 77: 117-121. http://dx.doi.org /10.2754/avb200877010117

[15] Kasiita H, Mugisha S, Rweog I, et al. Human serology survey in three sub-counties adjacent to Lake Mburo National Park in Kiruhura District, Uganda. Makerere University-International Development Research Centre, Canada. Project Report. 2012.

[16] Zein AM, Sabahelkhier MK. Prevalence of Brucellosis among High Risk Groups in Northern State, Sudan. Nova Journal of Medical and Biological Sciences. 2016; 4(1).

[17] Ahmed MO, Elmeshri SE, Abuzweda AR, et al. Seroprevalence of brucellosis in animals and human populations in the western mountains region in Libya, December 2006-January 2008. Euro Surveill. 2010; 15(30): 19625-8.
[18] Agasthya AS, Isloor S, Krishnamsetty P. Seroprevalence Study of Human Brucellosis by Conventional Tests and Indigenous Indirect Enzyme-Linked Immunosorbent Assay. The Scientific World Journal. 2012. PMid:22566755 http://dx.doi.org/10.1100/2012/10 4239

[19] Kubuafor D, Awumbila B, Akanmori B. Seroprevalence of brucellosis in cattle and humans in the Akwapim-South district of Ghana: public health implications. Acta Tropica. 2000; 76(1): 45-48. http://dx.doi .org/10.1016/S0001-706X (00)00088-7

[20] Frimpong S, Gebresenbet G, Bosona T, et al. Animal Supply and Logistics Activities of Abattoir Chain in Developing Countries: The Case of Kumasi Abattoir, Ghana. Journal of Service Science and Management. 2012; 5: 20-27. http://dx.doi.org/10.4236/j ssm. 2012.51003

[21] Kunda J, Fitzpatrick J, Kazwala R, et al. Health-seeking behaviour of human brucellosis cases in rural Tanzania. BMS Public Health. 2007; 7(1): 315. PMid:17980046 http://dx.doi.org/10.1186 /1471-2458-7-315

[22] Mukhtar F, Kokab F. Brucella serology in abattoir workers. J Ayub Med Coil Abbottbad. 2008; 20(3): 57-61. PMid:19610518

[23] Cadmus SIB, Ijagbone IF, Oputa HE, et al. Serological survey of brucellosis in Livestock animals and workers in Ibadan, Nigeria. African Journal of Biomedical Research. 2006; 9: 3.

[24] Al-Sekait MA. Seroepidemiological survey of brucellosis antibodies in Saudi Arabia. Annals of Saudi Medicine. 1999; 19: 219-222. PMid: 17283457

[25] Ramos TRR, Pinheiro Junior JW, Moura Sobrinho PAD, et al. Epidemiological aspects of an infection by Brucella abortus in risk occupational groups in the microregion of Araguaina, Tocantins. Brazilian Journal of Infectious Diseases. 2008; 12: 133-138. PMid:18641850 http://dx.doi.org/10.1590/S1413-86702008000200007

[26] Minas M, Minas A, Gourgulianis K, et al. Epidemiological and clinical aspects of human brucellosis in Central Greece. Japanese Journal of Infectious Diseases. 2007; 60(6): 362. PMid:18032835

[27] Swai E, Schoonman L. Human brucellosis: seroprevalence and risk factors related to high risk occupational groups in Tanga Municipality, Tanzania. Zoonoses and Public Health. 2009; 56(4): 183187. PMid:18811674 http://dx.doi.org/10.1111/j.1863-2 378.2008.01175.x

[28] De Massis F, Di Girolamo A, Petrini A, et al. Correlation between animal and human brucellosis in Italy during the period $1997-$ 2002. Clin Microbiol Infect. 2005; 11: 632-6. PMid:16008615 http://dx.doi.org/10.1111/j.1469-0691.2005.01204.x

[29] Al-Shamahy HA, Wright SG. A study of 235 cases of human brucellosis in Sana'a, Republic of Yemen. East Mediterr Health J. 2001; 7: 238-46. PMid:12596975

[30] Kozukeev TB, Ajeilat S, Maes E, et al. Centers for Disease Control, Prevention (CDC). Risk factors for brucellosis-Leylek and Kadamjay districts, Batken Oblast, Kyrgyzstan, January-November, 2003. MMWR Morb Mortal Wkly Rep. 2006; 55(Suppl 1): 31-4.

[31] Karimi A, Alborzi A, Rasooli M, et al. Prevalence of antibody to Brucella species in butchers, slaughterers and others. East Mediterr Health J. 2003; 9: 178-84. PMid:15562749

[32] el-Razik KA, Desouky HM, Ahmed WM. Investigations on brucellosis in Egyptian Baladi Does with emphasis on evaluation of diagnostic techniques. Pak J Biol Sci. 2007; 10: 342-8. PMid:19070039 http://dx.doi.org/10.3923/pjbs.2007.342.348

[33] Lobna MAS, Khoudair MR, Osman SA. Sero Diagnosis of Brucellosis by Using Simple and Rapid Field Tests with Emphasis on Some Possible Risk Factors in Humans Global Veterinaria. 2014; 12 (3): 320-325. 